\title{
Development of High Performance (Mechanical and Wear Properties) of AA 6061-Hybrid Nano Composites Via Liquid Metallurgy Route
}

Hussain J. M. Al-Alkawi ${ }^{*}$, Abduljabbar Owaid Hanfesh², Saja Mohammed Noori Mohammed Raouf ${ }^{3}$

\section{Authors affiliations:}

1*) Electromechanical Eng.

Dep., University of Technology, Baghdad -Iraq.

Alalkawi2012@yahoo.com

2) Electromechanical Eng.

Dep., University of Technology,

Baghdad -Iraq.

aljabbara.2007@yahoo.com

3) Electromechanical Eng. Dep., University of Technology, Baghdad -Iraq.

sema.semo@yahoo.com

\section{Paper History:}

Received: $16^{\text {th }}$ Oct. 2018

Revised: $4^{\text {th }}$ Dec. 2018

Accepted: 30 ${ }^{\text {th }}$ Mar. 2019

\begin{abstract}
This research is devoted to study the influence of different weight percent concerning to the additions of $\mathrm{Ti}$ and $\mathrm{Cu}$ on mechanical and tribological properties of AA6061. The composite materials consist of different weight percentage of $\mathrm{Ti}(0.2,0.4$, and 0.6$) \mathrm{wt} \%$ and constant weight percentage of $\mathrm{Cu}(0.2) \mathrm{wt}^{\mathrm{O}} \%$ which were fabricated by liquid metallurgy route technique. Microstructural characterization and phases have been examined by using SEM (scanning electron microscopic).SEM examination showed uniform distribution of nano Ti and $\mathrm{Cu}$ in AA6061. The consequences of mechanical tests demonstrated clear enhancement in mechanical properties, such as ultimate tensile strength, yield strength, young modulus, ductility $\%$ and hardness at additive percentage of $0.4 \%$ $\mathrm{Ti}+0.2 \% \mathrm{Cu}$ nano particles incorporated into molten AA6061. Percentage of enhancement ultimate tensile strength is about $73.3 \%$, yield strength about $82.7 \%$, young modulus is about $21.2 \%$, the Vickers hardness about $42.6 \%$ and the decreasing in ductility was about $25.2 \%$ compared with the metal matrix (AA6061). The wear rate test was performed by using pin on disc rig for both hybrid nano composite and base metal (AA6061) under various loads (10,15and 20) $\mathrm{N}$ with sliding speed (1.282) $\mathrm{m} / \mathrm{sec}$ at a $(10)$ min's time. The results showed a decrease in wear rate at $0.4 \% \mathrm{Ti}+0.2 \% \mathrm{Cu}$ compared with the base metal (AA6061). Improvement percentage of wear rate is about $105 \%$ at $20 \mathrm{~N}$ load.
\end{abstract}

Keywords: Hybrid Nano Composites, Mechanical Properties, Tribological Properties, Microstructure.

$$
\begin{aligned}
& \text { تطوير الهداء العالي للخواص الميكانيكة والترايبولجية للمركب النانوي الهجين } \\
& \text { لسبيكة المنيوم } 6061 \text { بواسطة السباكة المتحركة } \\
& \text { حسين جاسم محد العلكاوي ، عبد الجبار عويد حنفش ، سبحى محد نوري محمد رؤوف }
\end{aligned}
$$

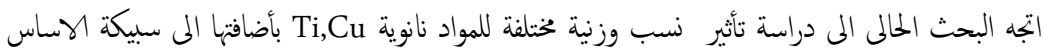

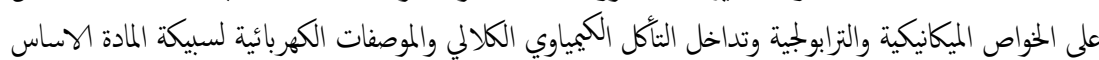

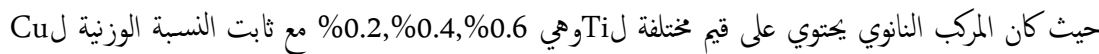

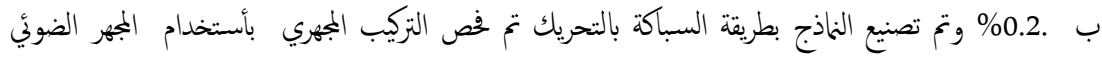

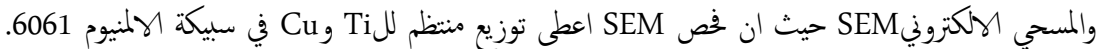

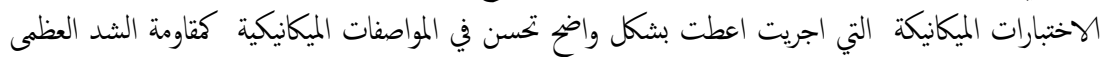

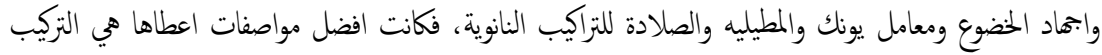

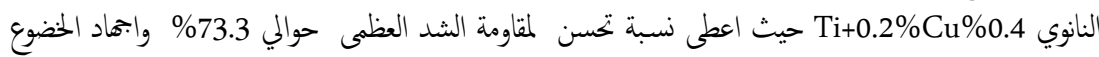

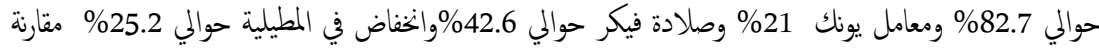

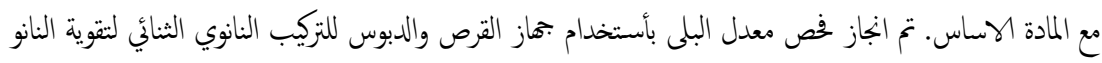




$$
\begin{aligned}
& \text { والمعدن الاساس (AA6061 ) تحت عدة احمال (N 10,15,20 ) بسرعة m/sec1.282 وبزمن }
\end{aligned}
$$

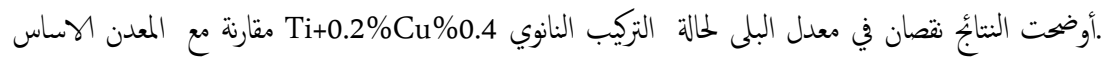

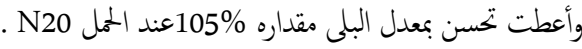

$$
\begin{aligned}
& \text { الكلمات المفتاحية: مركبات النانوية الهجينة,الخصائص الميكانيكية,خصائص البلى ,التزكيب المجهري }
\end{aligned}
$$

\section{Introduction}

Aluminum metal matrix nano composites (AMMNCs) have been utilized in many applications such as automotive, construction, and aerospace since they have the advantage of high ratio of strength to weight [1].AMCs containing two or more reinforcement materials have found commercial application because they can be manufactured economically by conventional methods. Moreover, they are distinguished by feasibility, good wear resistance, enhance strength, elastic modulus and low density. [2] The main properties that the applications of aluminum are based can be summarized as low density, high mechanical strength and high corrosion resistance as well as high ductility, and these reasons lead to a decrease in the cost of works [3]. Nandakumar et al. (2018)[4] studied hybrid metal matrix aluminum composites. Graphite is chosen as reinforcement material. The reinforcement materials were added and by stir-casting method the cast components were produced and are subjected to various tests to find their improved Properties. The composites show a $15-17 \%$ increase in tensile strength and $17-21 \%$ increase in yield strength mainly due to $\mathrm{SiC}$ and a maximum of $3 \%$ decrease in both properties due to the addition of Graphite. It shows a $5-8 \%$ increase in hardness where similarly $\mathrm{SiC}$ contributes to this and Graphite reduced Hardness by $1 \%$ at $4 \%$ composition. Wear test reveals that Graphite is successful at reducing wear by $16 \%$ in the Sample 7 (Al/SiC-13p/Gr-4p. Sozhamannan et al. (2018)[5] studied multiple reinforcements emerged to promote the wear resistance properties. The wear showing of hybrid composites were all set by stir casting process and wear showing were rated by pin on disc process at dry condition with changing the applied load of $40 \mathrm{~N}$ to $80 \mathrm{~N}$ and sliding velocity of $1.5 \mathrm{~m} / \mathrm{s}$ to $4.5 \mathrm{~m} / \mathrm{s}$. The results showed 6061 $\mathrm{Al} / \mathrm{Nano} \mathrm{TiCp} / \mathrm{Gr}$ hybrid composites were produced by stir casting process. The reinforcement particles were found dispensed uniformly in the matrix. The wear average of hybrid composite rises with rises of applied load and sliding velocity but wear rate is 4.7 percentages minimize the unreinforced $6061 \mathrm{Al}$ matrix materials. Manivannan et al. (2018)[6] studied metal matrix nano composite (MMNC) of $\mathrm{Al} 6061$ reinforced with $1.2 \mathrm{wt} \% \mathrm{Al} 203$ and $0.5 \mathrm{wt} \% \mathrm{Gr}$ (Al$1.2 \mathrm{Al} 203-0.5 \mathrm{Gr}$ ) hybrid nano composite was prepared by ultrasonic assisted stir casting method. Dry sliding wear tests were performed as per the experimental. The parameters were optimized using desirability based multi response optimization technique to minimize the wear rate and coefficient of friction. Increase of speed reduces wear by supporting mechanically mixed tribolayer and increase of load decreases wear by the role of metal matrix layer. Ruban et al. (2018)[7] studied the tensile strength and hardness of Aluminum metal matrix composites AA6061reinforced with $\mathrm{ZrB}_{2}$ and $\mathrm{SiC}$. The metal matrix composite is prepared by using stir casting setup. The in situ fabricated $\mathrm{ZrB} 2$ and the reinforced $\mathrm{SiC}$ particles enhance the hardness and also the tensile strength of the metal matrix composite. The results indicated that $\mathrm{ZrB}_{2}$ and $\mathrm{SiC}$ particles were effective to increase the hardness and tensile strength of the metal matrix composite. Jagadeesh et al. (2018)[8] deal with fabrication of hybrid nano composite material including metal matrix Al6061, reinforcements of Silicon Carbide (SiC), Zirconia or Zirconium dioxide $\left(\mathrm{ZrO}_{2}\right)$ and Graphite (Gr) by incoming process. These reinforcements are taken by a growing of $0.75 \%$ for each sample. Hardness of the composites has safely afflicted by the turnout of reinforcement content. Then the Tensile strengths are raises as well as decreases with grow up amount of reinforcements. Also the influence of thermal conductivity shows increase of reinforcements decreases the rate of thermal conductivity. Sivapuram et al. (2017)[9] studied the tests samples were manufactured using $\mathrm{Al}$ 6061 as base metal by adding 2\% Boron Carbide nanopowder by weight fraction and varying composition of Silicon Carbide nanopowder in the matrix of $5 \%, 10 \%, 15 \%, 20 \%$ by weight fraction manufactured by in-situ stir casting technique. Experimental results revealed that yield strength, elongation $\%$ and average crush load, specific energy absorption capacity was increased by reinforcing $5 \%$ $\mathrm{SiC}$ to $\mathrm{Al} 6061+2 \%$ B 4 C. $20 \mathrm{wt} \% \mathrm{SiC}$ reinforcement shows that good result in UTS and fracture strength and initial peak load, energy absorbed during the crush. Sivapuram et al. (2017)[10] investigated the wear rate of A16061/SiC metal matrix composite (MMC) has been promoted by reinforcing Zirconium ( $\mathrm{Zr}$ ) particles to the molten Al6061/SiC metal matrix composites (MMC) by stir casting process. The wear rate was examined utilizing pin on disk wear examiner. An attempt has been made to blend $2 \%$ of Zr with Al6061 alloy by changing Sic in 10, 15 and $20 \%$. The wear resistance of $\mathrm{Al} 6061 / \mathrm{SiC}$ has been afflicated safely due to the uniform division of $\mathrm{Zr}$ particles in the matrix. Sozhamannan et al. (2017) [11] deal with aluminum based hybrid composites. The wear showing hybrid composites were produced by stir casting process and wear shows were rated by pin on disc process at dry condition with changing applied load of $40 \mathrm{~N}$ to $80 \mathrm{~N}$ and sliding velocity of $1.5 \mathrm{~m} / \mathrm{s}$ to $4.5 \mathrm{~m} / \mathrm{s}$. Results show that wear rate raises in either increasing applied load or sliding velocity and the applied load and sliding velocity safely affected the wear volume waste in hybrid composites. The existence of multiple reinforcements in the 
matrix enhance the wear performances matched to the $6061 \mathrm{Al}$ alloy. Chowdary et al. (2013)[12] studied composites of different weight \% of Graphite and $\mathrm{SiC}$ in $\mathrm{Al}$ alloy. The composites were prepared by pressure die casting technique and the specimens were subjected to artificial ageing for 1720 for 2, 4 and 6 hours. Results showed that ultimate tensile strength and Young's modulus of the hybrid composites increases with raising in the percentage reinforcements. But at higher percentages there is not much significant change in both the cases. Nagaral et al. (2013) [13] examined Aluminum metal matrix composites (MMCs). The composite is produced by using Liquid Metallurgy Route (Stir Casting process), Tensile strength of prepared composites is higher in case of composites, when compared to cast Al606. Addendum of $6 \mathrm{wt} \% \mathrm{Al}_{2} \mathrm{O}_{3}$ raises the tensile strength considerably with attention to base matrix Al6061. Hardness of the produced composites is higher than the base AL6061 alloy. Ductility minimizes with the addendum of $\mathrm{Al} 2 \mathrm{O} 3$ particles, which causes to lower the percentage extention as compared to base alloy. Addition of graphite content increased the percentage of elongation compared to composites containing $\mathrm{Al}_{2} \mathrm{O}_{3}$ particles.

The objective of this study:

1. To fabricate the hybrid composites at various amounts of titanium (Ti), 0.2,0.4,0.6 wt.\% keeping copper (cu) of $0.2 \mathrm{wt} \%$ by using stir casting technique with AA6061 base metal.

2. To study the microstructural feature of metal matrix composites and mechanical properties such as, ultimate tensile strength, yield stress, young modulus, ductility and failure strain of composite.

3. To estimate the tribological properties of composites by using pin on disc wear test rig.

\section{Experimental Work}

In this work the hybrid nano composites have been studied contain AA 6061 which is reinforced with titanium ( $\mathrm{Ti}$ ) with $(0.2,0.4,0.6) \%$ wt. and constant content of copper with $0.2 \%$ wt were fabricated by using stir casting technique. AA6061 has been selected because of extremely corrosion resistance and moderate strength [14]. (HAMMCs) has been fabricated via stir casting. This method is one of the economical techniques to enhance the mechanical, electrical and tribological properties of the composites. The procedure can be summed up by the following steps.

1. Melting the AA6061 using electrical furnace at $850 \dot{c}$ for 25 minute (furnace capacity of is $1 \mathrm{~kg}$ )
2. Heated the nano hybrids reinforced materials ( $\mathrm{Ti}$ and $\mathrm{cu}$ ) with particles size (15-50 nm for titanium and $15 \mathrm{~nm}$ for copper) to $200 \dot{\mathrm{c}}$ and added it to the melt of AA6061 by using these weight percentage $(0.2 \% \mathrm{Ti}), \quad(0.4 \% \mathrm{Ti}), \quad(0.6 \% \mathrm{Ti})$ and $(0.2 \% \mathrm{Cu})$.

3. Stirring the mixture at speed of $450 \mathrm{rpm}$ for 4 minutes using graphite mixer.

4. Heat the mold to $250 \dot{\mathrm{c}}$ then poured it to the mold.

5. The cast iron mold (14 $\mathrm{mm}$ diameter and 200 $\mathrm{mm}$ length) gives the shape and geometry of billet composite.

The temperature $(850 \dot{\mathrm{c}})$, time (4 minutes), mold temperature $(250 \dot{\mathbf{c}})$, nano hybrid reinforcements temperature $(200 \dot{\mathbf{c}})$ and stirring speed $(450 \mathrm{rpm})$ were adopted as Ref [15].

\subsection{Chemical Analysis}

Chemical analysis of the base metal (AA6061) was done at state company for inspection and engineering rehabilitation in Iraq (SIER). The results which are compared to the American standard are reported in table (1)[16]. Nano Ti (grain size 30-50 nm) and $\mathrm{Cu}$ (grain size $15 \mathrm{~nm}$ ).

\subsection{Specimen Geometry}

The material was produced from casting mould with dimension (14 $\mathrm{mm}$ dia. and $200 \mathrm{~mm}$ length). Dimension of tensile specimen was conducted according to the ASTM E8-E8M [17] in the figure below.

\subsection{Stress - Strain Measurement System}

Tensile test was performed in department of production engineering and metallurgy using device type DWD-200E with capacity $200 \mathrm{KN}$.

\subsection{Wear Properties Test}

Wear test was carried out in the department of production engineering and metallurgy. Testing machine (pin on disc) was utilized to carry out wear test. The specimens were (base metal plus hybrids nano composites) with different reinforced material $\mathrm{Ti}$ and $\mathrm{Cu} 0,0.2,0.4$, and $0.6 \%$ Tiw wt. \% with constant amount of $\mathrm{Cu} 0.2 \mathrm{wt} \%$ were conducted to obtain required tribological properties. Each specimen is weighted before and after wear test utilizing a digital balance having a precision of \pm $0.0001 \mathrm{gm}$. Wear specimens were cleaned by Acetone before test and then sample was placed on the pin handle and it prepared for wear test. The wear test was performed at a sliding speed of $1.282 \mathrm{~m} / \mathrm{sec}$ based on $490 \mathrm{rpm}$. The total time was 10 minutes under room temperature. The dimensions of specimen's are $10 \mathrm{~mm}$ in diameter and $20 \mathrm{~mm}$ in length. Figure (3) shows the devices of wear test with wear sample.

Table (1): show a chemical compositions of base metal and nano reinforcements

\begin{tabular}{|c|c|c|c|c|c|c|c|c|c|c|}
\hline Element Wt. $\%$ & $\mathrm{Cr}$ & $\mathrm{Zn}$ & $\mathrm{Co}$ & $\mathrm{Si}$ & $\mathrm{Ti}$ & $\mathrm{Ma}$ & $\mathrm{Mg}$ & $\mathrm{Fe}$ & others & $\mathrm{Al}$ \\
\hline Standard[16] & $0.04-0.35$ & Max 0.25 & $0.15-0.4$ & $0.4-0.8$ & Max 0.15 & $0.8-1.2$ & Max 0.15 & Max0.7 & 0.05 & Balance \\
\hline Experimental & 0.18 & 0.13 & 0.28 & 0.61 & 0.08 & 0.96 & 0.11 & 0.54 & - & Balance \\
\hline \multicolumn{8}{|c|}{ Nano Ti } & \multicolumn{7}{c|}{ Nano Cu } \\
\hline Purity $\%$ & \multicolumn{1}{|c|}{ Color } & Nano Size & \multicolumn{1}{c|}{ Purity $\%$} & \multicolumn{1}{c|}{ Color } & Nano Size \\
\hline
\end{tabular}




\begin{tabular}{|l|l|c|c|c|c|}
\hline 99.9 & Black grey & $30-50 \mathrm{~nm}$ & $>99.9$ & Brwon & $15 \mathrm{~nm}$ \\
\hline
\end{tabular}

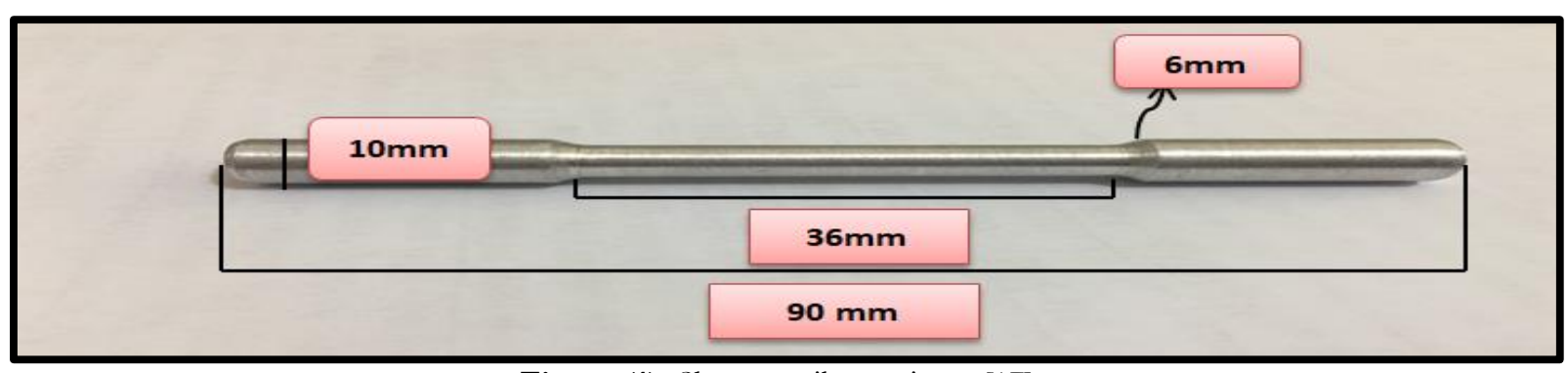

Figure (1): Show tensile specimen [17]

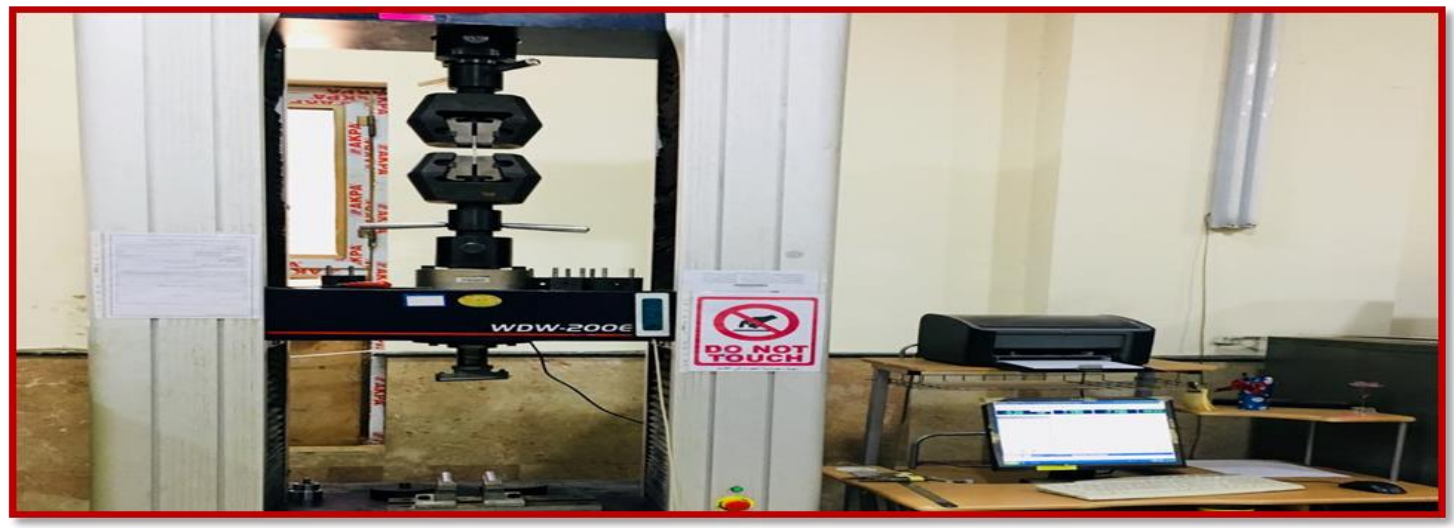

Figure (2): tensile testing machine

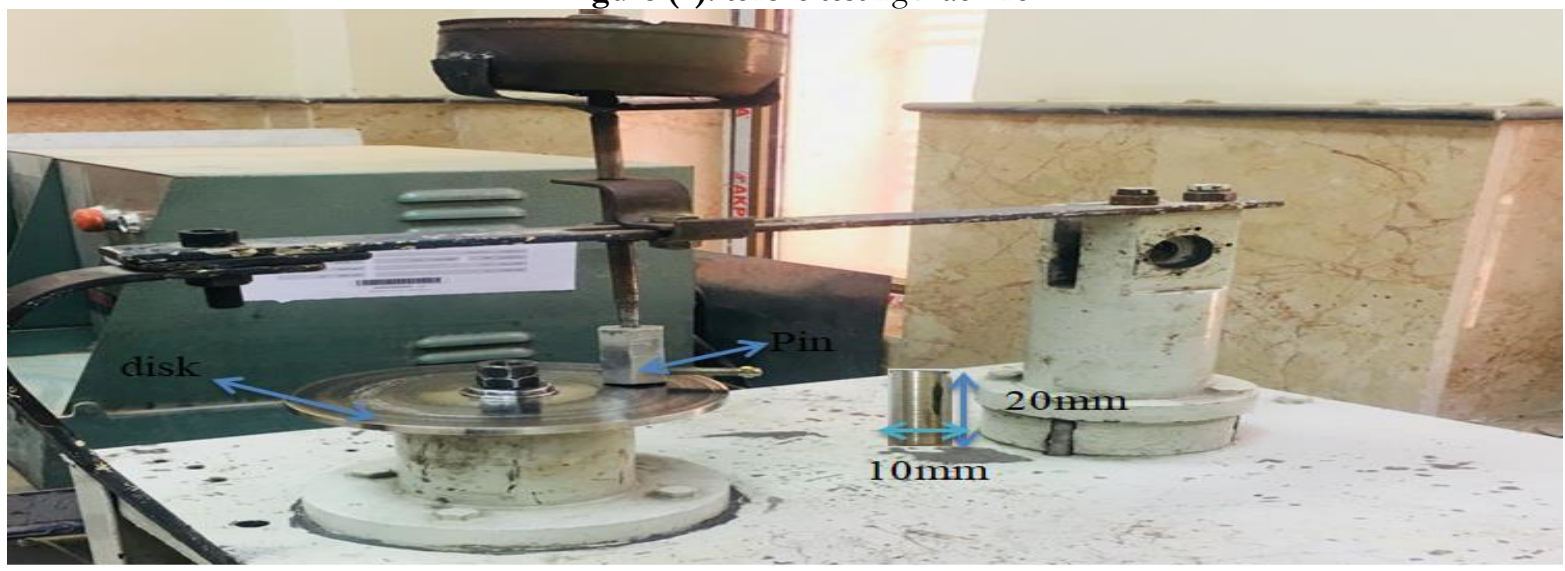

Figure (3): shows the device of wear with the sample

\section{Experimental Results and Discussion 3.1 Microstructure:}

The SEM images with various weight percentages of $\mathrm{Ti}$ and $\mathrm{Cu}$ particles are shown in figure (4) under the magnification factor of $1 \mathrm{kX}$.

It is observed that the nano hybrid particles are uniformly distributed on the metal matrix. It is noted that the mean dendrite sizes of the as-cast composite $(0.4 \% \mathrm{Ti}+0.2 \% \mathrm{Cu})$ have smaller dendrite sizes compared to the as -cast and other composites. The adding of the amount of nano hybrids particles more than the above value leads to a slight improvement in the dendrite sizes compared to the best nano composite of $(0.4 \% \mathrm{Ti}+0.2 \% \mathrm{Cu})$. It clear that there is good connection among the hard $\mathrm{Ti}$ and $\mathrm{Cu}$ particles with as- cast material. The presence of stiffer and harder $\mathrm{Ti}+\mathrm{Cu}$ particles enhance the mechanical and electrical properties of the alloy. Also, the reinforcement matrix interfaces are free of porosity because of the enhancement of wettability by including $\mathrm{Ti}$ and $\mathrm{Cu}$ [18] The good dispersion of the hybrid nano reinforced material in the base metal leads to great improvement in mechanical, tribological, electrical and magnetic properties [19]. Micrographs of composites show homogeneous dispersion of $\mathrm{Ti}$ and $\mathrm{Cu}$ in the base metal and also show irregularly size of $\mathrm{Ti}$ and $\mathrm{Cu}$. It is clear that the particles chains and aggregation are seen and concentrated at the boundaries of grains.

\subsection{Mechanical properties:}

The mechanical properties, such as, ultimate tensile strength (UTS), yield stress (YS), modulus of elasticity(E), elongation percentage (ductility) and failure strain were extracted from the tensile stressstrain curves as shown in figure (5). 
It is clear that all the mentioned properties, of hybrid nano composites are greater than the as cast AA6061. While elongation percentage of all composites is lower than the metal matrix. It is also clear from figure (6) that the ultimate strength increased when the wt $\%$ of reinforced materials increased up to $0.4 \% \mathrm{Ti}+\mathrm{o} .2 \% \mathrm{cu}$ and then reduced but still these properties are higher than the unreinforced alloy.

The (UTS), (YS) and (E) show high value for the case of $(0.4 \% \mathrm{Ti}+0.2 \% \mathrm{Cu})$ composite and decrease while increasing nano particles above $0.4 \% \mathrm{Ti}+0.2 \% \mathrm{Cu}$. The properties are increased by $73.3 \%, 82.7 \%$ and $21.2 \%$ respectively compared to metal matrix. Improvements in strength (UTS, YS and E) are possibly coming from the thermal mismatch between AA6061 and nano particles of $\mathrm{Ti}+\mathrm{cu}$. This mechanism increases the dislocation density of the matrix and resulted in increasing the strength value is observed with increasing the hybrids nano particles from $75 \mathrm{MPa}$ for AA6061 to $130 \mathrm{MPa}$ for AA6061 0.4\% Ti+0.2\% cu represents an extent of improvement in ultimate tensile value of $73.3 \%$

The variation of ductility against hybrid Wt. $\%$ is given in figure (7).

The composites exhibited lower ductility than that of as- cast samples. It is noted that the change in ductility of the composites is dependent on the distribution of $\mathrm{Ti}$ and $\mathrm{cu}$, grain size and porosity. The above findings agreed well with what concluded by Rajasekhar.Sivapuram ${ }^{1}$ et al [10]. The ductility has improved by $25.2 \%$ compared to the monolithic alloy. The lower ductility of composite samples may be due to plastic deformation of mixed soft metal matrix and reinforcement is more than the base metal itself.
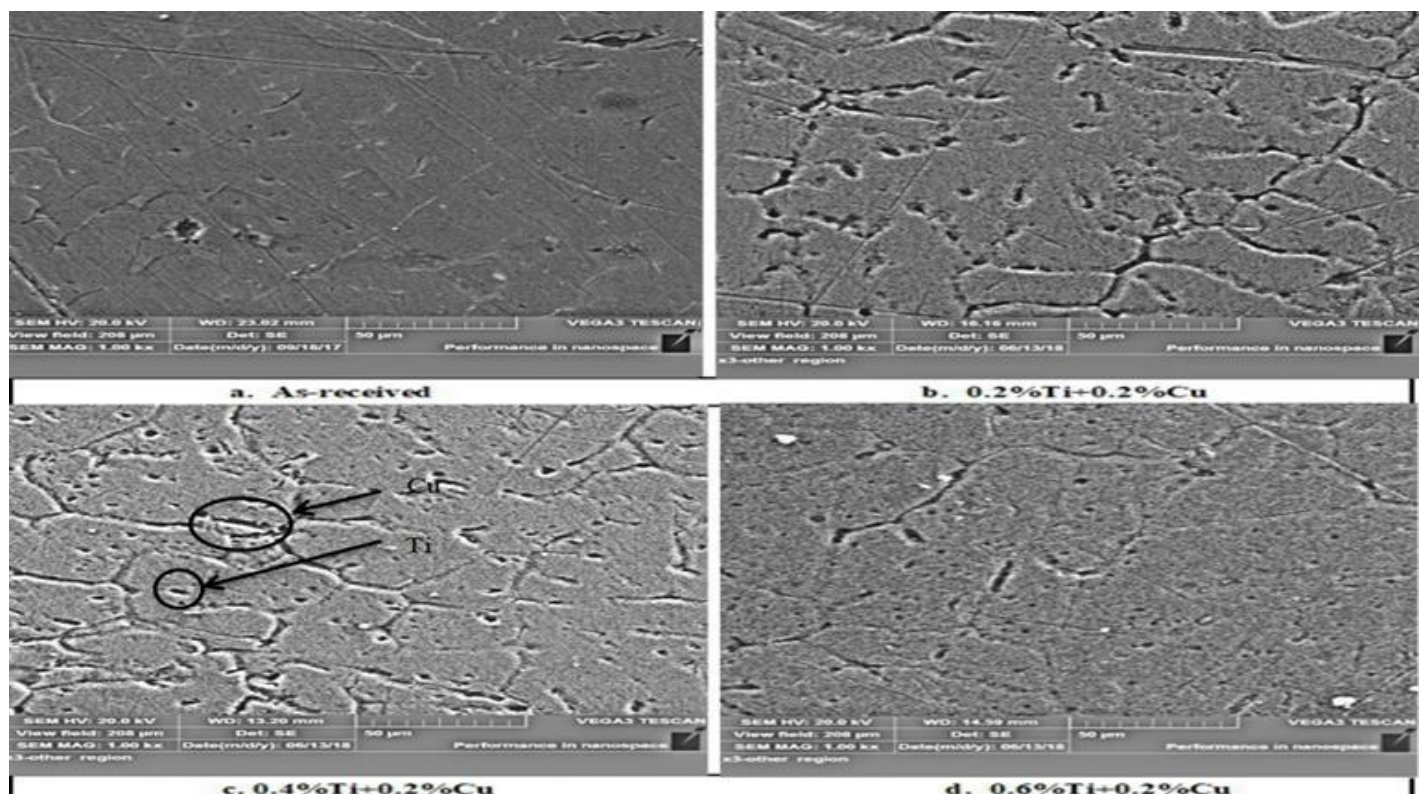

Figure (4): Microstructure of hybrids Nano composites by using SEM.

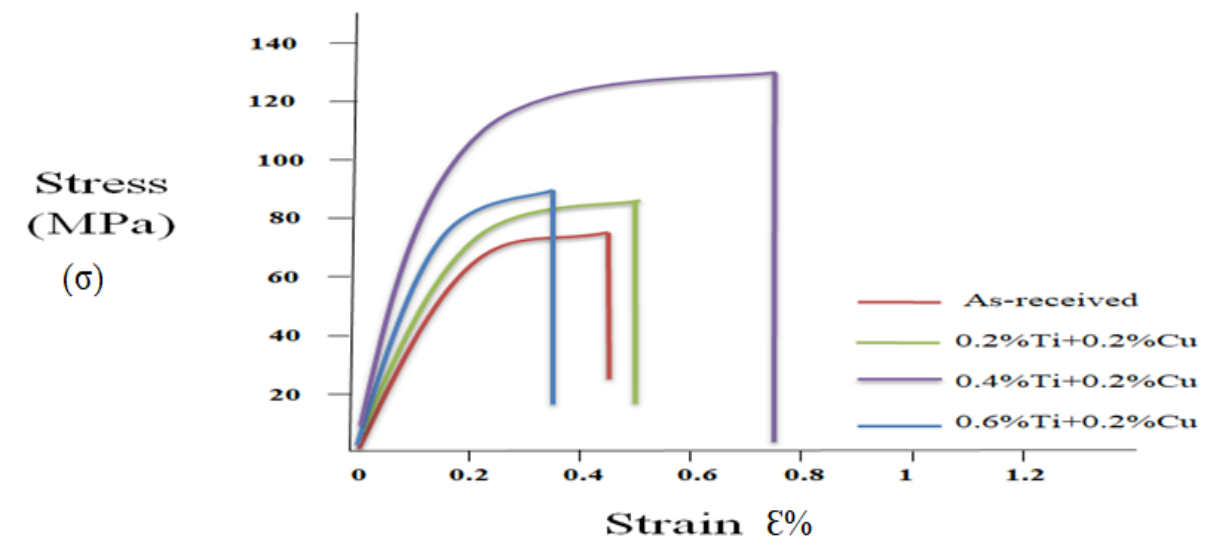

Figure (5): curve of stress-strain for AA6061/ hybrids Nano composites 


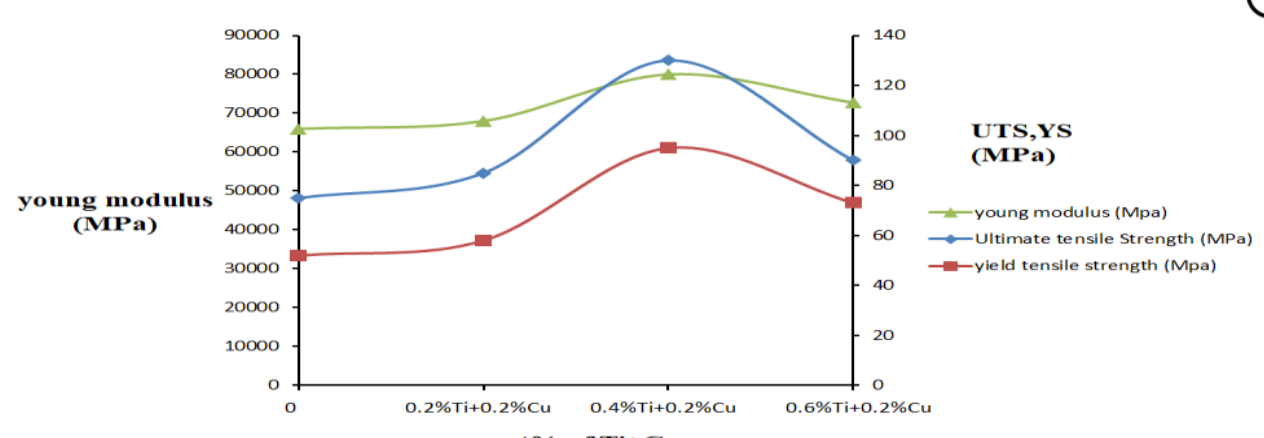

wt \% of $\mathrm{Ti}+\mathrm{Cu}$

Figure (6): Shows the increase in mechanical properties

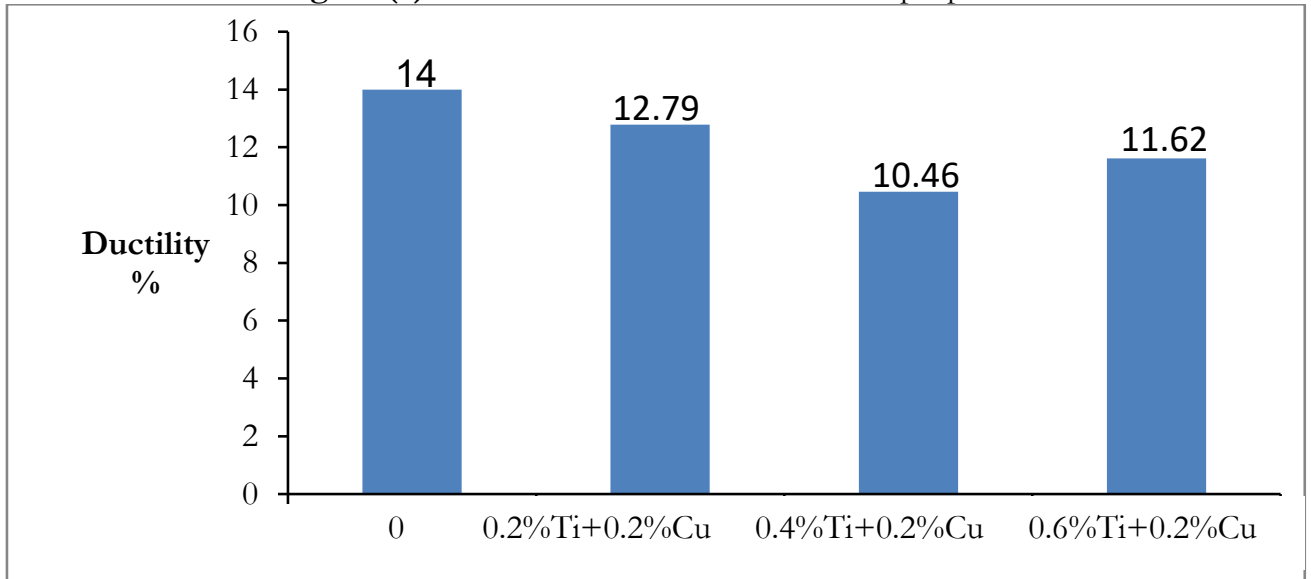

Figure (7): Shows variation of ductility of AA6061 before and after the addition of various $\mathrm{wt} \%$ of $\mathrm{Ti}+\mathrm{Cu}$ nano material

\subsection{Hadness:}

Table (3) and Figure (8) show the HV hardness conducted on AA6061 and the AA6061 hybrid composites containing different $\mathrm{wt}^{\mathrm{\%}} \mathrm{\textrm {A }}$ of $\mathrm{Ti}$ and $\mathrm{Cu}$. It is clear that fig $(5,6)$ show a significant increase in $\mathrm{HV}$ of the AA6061 has been happened with the addition of $\mathrm{Ti}+\mathrm{Cu}$ particles being hard; this property contributes positively to improve the hardness of composites. The presence of harder nanoparticles leads to enhance the total hardness of the sample and could be attributed to the relatively high hardness of nanoparticles themselves.

Based on the experimental results given in table (4) and figure (7), nano composites with $(0.4 \% \mathrm{Ti}+0.2 \% \mathrm{Cu}) \mathrm{wt}^{0} \%$ has the best hardness. HV hardness improves by $42.6 \%$ compared to the base metal . It is clear that $\mathrm{HV}$ of the composites is greater than that of zero nano alloy. The uniformed dispersion of $\mathrm{Ti}$ and $\mathrm{Cu}$ particles improves the $\mathrm{HV}$ when the particles of hybrid nano reinforced materials are harder than the base alloy which acts as a reinforcing phase and obstacles the movement of dislocation .The greatest HV hardness obtained for composite containing $(0.4 \% \mathrm{Ti}+0.2 \% \mathrm{Cu})$ which is about $64.18 \%$ and the lowest value is 45 for base metal. The above findings agreed well with what had been concluded by Gaurav Mahaja et al [18], who found that $\mathrm{HV}$ increases by $38 \%$ upon adding hybrid nano material, Sic, and $\mathrm{TiB}_{2}$.

\subsection{Wear Results:}

The experimental wear results such as wear rate, weight loss and net volume were calculated for various amount percentages of $\mathrm{Ti}$ and constant $\mathrm{Cu}$ particles are given in table (4).

Figure (9) illustrates the wear rate of AA6061 and composites variation with amount of hybrids nano particles.

It is seen that a decrease in wear rate after the addition of nano particles compared to the matrix AA6061. This property is due to the incorporation of hard $\mathrm{Ti}+\mathrm{Cu}$ particle in the AA6061. Also it is observed from figure (9) that the decreasing trend of wear rate with increase in $\mathrm{wt}^{\mathrm{t}} \%$ of hybrid nano particle up to $0.4 \% \mathrm{Ti}+0.2 \% \mathrm{Cu}$ weight percentage and then increased slightly. Wear rate is $0.03907 \times 10^{-3}$ $\mathrm{mm}^{3} / \mathrm{mm}$ for the base metal at applied load of $20 \mathrm{~N}$ and sliding speed of $1.282 \mathrm{~m} / \mathrm{sec}$ based on $490 \mathrm{rpm}$. But this value decreases to $0.01648 \times 10^{-3} \mathrm{~mm}^{3} / \mathrm{mm}$ for $(0.4 \% \mathrm{Ti}+0.2 \% \mathrm{Cu})$ composite for the same conditions as seen in figure (8).

Table (3): shows the micro Vickers hardness of hybrid nano composites and base metal

\begin{tabular}{|c|c|c|c|}
\hline \multicolumn{4}{|c|}{ Vicker hardness } \\
\hline \multirow{2}{*}{0} & $\begin{array}{c}0.2 \% \mathrm{Ti}+ \\
0.2 \% \mathrm{Cu}\end{array}$ & $\begin{array}{c}0.4 \% \mathrm{Ti} \\
+0.2 \% \mathrm{Cu}\end{array}$ & $\begin{array}{c}0.6 \% \mathrm{Ti}+ \\
0.2 \% \mathrm{Cu}\end{array}$ \\
\hline 45 & 47.13 & 64.18 & 59.21 \\
\hline
\end{tabular}

Table (4): Experimental tribological properties

\begin{tabular}{|c|c|c|c|c|}
\multicolumn{5}{|c|}{ results } \\
$\begin{array}{c}\mathrm{Wt} \% \text { of } \\
\mathrm{Ti}+\mathrm{Cu}\end{array}$ & 0 & $\begin{array}{c}0.2 \% \mathrm{Ti}+ \\
0.2 \% \mathrm{Cu}\end{array}$ & $\begin{array}{c}0.4 \% \mathrm{Ti}+ \\
0.2 \% \mathrm{Cu}\end{array}$ & $\begin{array}{c}0.6 \% \mathrm{Ti}+ \\
0.2 \% \mathrm{Cu}\end{array}$ \\
\hline Load $(\mathrm{N})$ & \multicolumn{5}{|c|}{ Weight loss $(\mathrm{gm})$} \\
\hline 10 & 0.007 & 0.006 & 0.003 & 0.005 \\
15 & 0.017 & 0.007 & 0.004 & 0.006 \\
20 & 0.029 & 0.008 & 0.006 & 0.007 \\
\hline Load $(\mathrm{N})$ & \multicolumn{5}{|c}{ Volume loss $\left(\mathrm{mm}^{3}\right)$} \\
\hline
\end{tabular}


NJES 22(2)143-150, 2019

Al-Alkawi et al.

\begin{tabular}{|c|c|c|c|c|}
\hline 10 & 14.463 & 10.911 & 6.921 & 8.232 \\
15 & 20.543 & 15.448 & 9.378 & 11.239 \\
20 & 26.098 & 19.117 & 12.691 & 15.706 \\
\hline Load $(\mathrm{N})$ & \multicolumn{4}{|c|}{ Wear rate $\times 10^{-3}\left(\mathrm{~mm}^{3} / \mathrm{s}\right)$} \\
\hline
\end{tabular}

\begin{tabular}{|l|l|l|c|c|}
\hline 10 & 0.01879 & 0.01417 & 0.008991 & 0.010695 \\
15 & 0.02668 & 0.02007 & 0.01211 & 0.0146 \\
20 & 0.03907 & 0.02483 & 0.01648 & 0.0204 \\
\hline
\end{tabular}

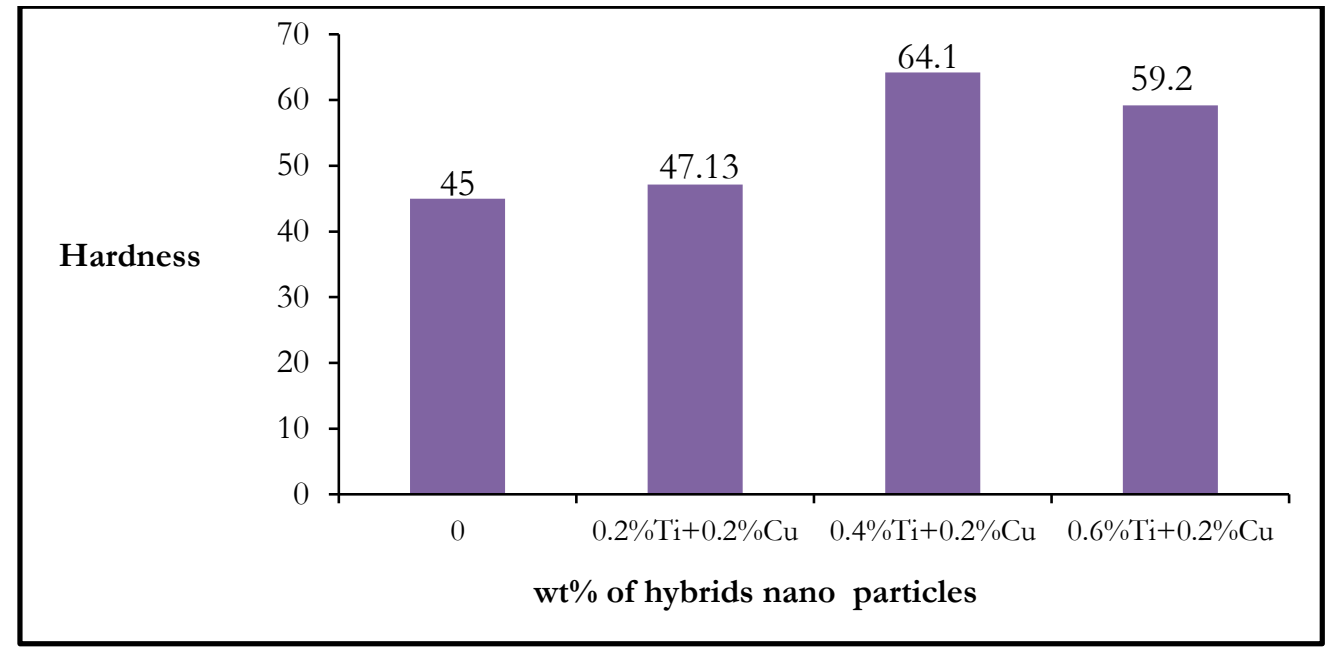

Figure (8): HV against the wt. of hybrids nano composites

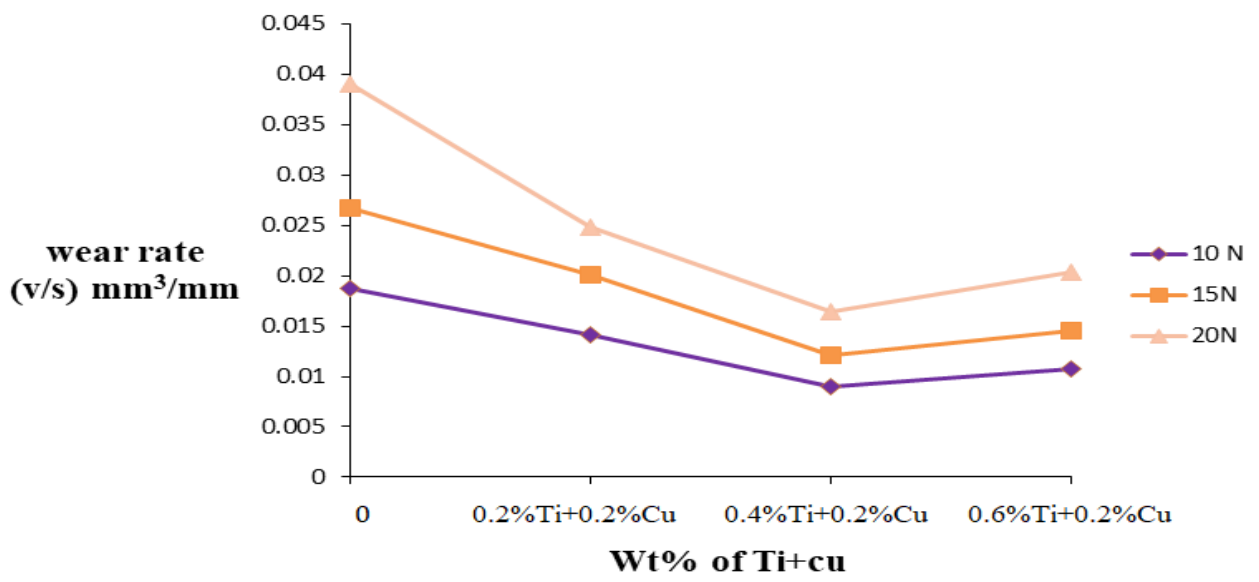

Figure(9): show wear rate behavior for AA6061/hybrid nano composites

\section{Conclusions}

1. The hybrid nano composites were fabricated by using stir casting technique with stirring speed $(450 \mathrm{rpm})$ and casting temperature $\left(850 \mathrm{C}^{\circ}\right)$ acquired higher mechanical and tribological when compared with zero nano (AA6061). The arrangement of $\mathrm{Ti}+\mathrm{Cu}$ nano-particles can be observed through microstructure inspection indicates that stir casting technique is the most suited way to fabricate composites.

2. Adding $\mathrm{Ti}$ and $\mathrm{Cu}$ nano particles to the composite significantly enhanced their ultimate tensile strength is about $73.3 \%$, yield stress is about $82.7 \%$ and hardness is about $42.6 \%$. But reduces the ductility by $25.2 \%$

3. Wear rate base alloy and composites have been studied at different loads, the results showed that the wear rate for hybrid nano composite with $0.4 \% \mathrm{Ti}+0.2 \% \mathrm{Cu}$ at $20 \mathrm{~N}$ shows lower wear rate of $0.1648 \times 10^{-3} \mathrm{~mm}^{3} / \mathrm{mm}$, with improvement factor of $137 \%$ compared to as-cast metal.

\section{Reference}

[1] R.L. Carlson., G.A. Kardomateas.and J.I.Craig "Mechanics of failure mechanisms in structures" 1 Sted, springer, Berlin, Germany, (2012).

[2] Mohsen H, Hamidreza B., "Fabrication and studying the mechanical properties of A336 alloy reinforced with $\mathrm{Al} 2 \mathrm{O} 3-10 \%$ vol. $\mathrm{ZrO}_{2}$ nanoparticles through stir casting", Advanced in Materials Physics and Chemistry, 1, 26- 30, (2011).

[3] P.G. Sheasby., R. Pinner., "The surface treatment and finishing of aluminum and its alloys" 6 th edition, ASM international, (2001).

[4] N. Nandakumar, "Experimental Investigation on mechanical properties of Al6061 Hybrid Metal Matrix Composite Reinforced with Silicon Carbide and Graphite", International Journal of Computer Sciences and Engineering, 6(5) May (2018).

[5] G.G. Sozhamannan, M. Mohamed Yusuf, G. Aravinda, G. Kumaresanb, K. Velmurugan, V.S. K.Venkatachalapathy," Effect Of Applied Load On The Wear Performance of $6061 \mathrm{Al} / \mathrm{Nano}$ Ticp/ Gr 
Hybrid Composites", Materials Today: Proceedings 5, 6489-6496, (2018).

[6] I. Manivannan, S. Ranganathan, S. Gopalakannan, S. Suresh, "Dry Sliding Wear behaviour of cast $\mathrm{Al} / \mathrm{Al} 203 / \mathrm{Gr}$ hybrid nanocomposite using response surface methodology", The 3rd International Conference on Materials and Manufacturing Engineering, (2018).

[7] S. Rajesh Ruban, Dr. K. Leo Dev Wins, Dr. M. Mahendra Boopathi and A. Arun Richard, "Evaluation of Mechanical Properties of Al-6061 Reinforced With ZrB2 -SiC Hybrid Metal Matrix Composites", International Journal of Mechanical Engineering and Technology (IJMET), 9(2)88-94, Feb. (2018).

[8] Jagadeesh.N, Senthil Kumar.A.P , Janaki.S, "Studies on Mechanical and Thermal Behaviors of Al6061- SiC-Gr-ZrO2 NanoHybrid Composites", IOP Publishing, (2018).

[9] Rajasekhar. Sivapuram, Hariprasada Reddy. Yedula, "An Experimental Investigation On Tensile Properties And Energy Absorption Capabilities Of Hybrid Nano Metal Matrix (Al 6061+B4C+SiC) Composites", International Journal of Advances In Engineering \& Technology, Apr., (2017).

[10] Rajasekhar Sivapuram, Hariprasada Reddy Yedula, "Experimental Investigation on Wear Rate of Al6061/SiC/Zr Hybrid Metal Matrix Composite", International Journal of Engineering Research in Mechanical and Civil Engineering (IJERMCE), 2(9) Sep. (2017).

[11] G. G. Sozhamannan, M. Mohamed Yusuf, G. Aravind, G. Kumaresan, "Effect of Applied Load on The Wear Performance of $6061 \mathrm{Al} / \mathrm{Nano}$ TiCP/ Gr Hybrid Composites", Materials Today: Proceedings 5, 6489.

[12] Yanamandala Raghuram Chowdary, C.Yuvaraj, K. Prahlada Rao, B. Durgaprasad, "Evaluation of Mechanical Properties of $\mathrm{Al} / \mathrm{SiC}-$ Graphite Hybrid Metal Matrix Composites", International Journal of Advanced Trends in Computer Science and Engineering, 2(6)286-289, (2013).

[13] Madeva Nagaral, V Auradi \& Ravishankar M K, "Mechanical Behaviour of Aluminium 6061 Alloy Reinforced With $\mathrm{Al}_{2} \mathrm{O}_{3}$ \& Graphite Particulate Hybrid Metal Matrix Composites", International Journal of Research In Engineering \& Technology (IJRET), 1(2)193-198, July (2013).

[14] Kumar, GB Veeresh, et al. "Studies on Al6061$\mathrm{SiC}$ and Al7075-Al2O3 metal matrix composites." Journal of Minerals and Materials Characterization and Engineering 9(1)43,(2010)

[15] Akbari, M. Karbalaei, H. R. Baharvandi, and O. Mirzaee. "Nano-sized aluminum oxide reinforced commercial casting A356 alloy matrix: Evaluation of hardness, wear resistance and compressive strength focusing on particle distribution in aluminum matrix." Composites Part B: Engineering 52 (2013): 262-268.

[16] Designation: B 211 - 03 "Standard Specification for Aluminum and Aluminum-Alloy Bar, Rod, and Wire", ASTM International ,(2009).
[17] Designation: E8/E8M"Standard test methods for tension testing of metallic materials " ASTM International, (2017).

[18] Gaurav Mahajan, Nikhil Karve, Uday Patil, P. Kuppan and K. Venkatesan, "Analysis of Microstructure, Hardness and Wear of $\mathrm{Al}-\mathrm{SiC}-\mathrm{TiB}_{2}$ Hybrid Metal Matrix Composite", Indian Journal of Science and Technology, 8(S2)101-105,Jan.(2015).

[19] U. Achutha Kini, S. S. Sharma, K. Jagannath, P. R. Prabhu, Gowri Shankar M. C., "Characterization Study of Aluminium 6061 Hybrid Composite", International Journal of Chemical, Molecular, Nuclear, Materials and Metallurgical Engineering 9(6),(2015). 